\title{
Prevalence of amino acid mutations in hepatitis $C$ virus core and NS5B regions among Venezuelan viral isolates and comparison with worldwide isolates
}

Rossana C Jaspe, Yoneira F Sulbarán, Maria Z Sulbarán, Carmen L Loureiro, Hector R Rangel and Flor H Pujol*

\begin{abstract}
Background: Recent reports show that R70Q and L/C91M amino acid substitutions in the core from different hepatitis $\mathrm{C}$ virus ( $\mathrm{HCV}$ ) genotypes have been associated with variable responses to interferon (IFN) and ribavirin (RBV) therapy, as well to an increase of hepatocellular carcinoma (HCC) risk, liver steatosis and insulin resistance (IR). Mutations in NS5B have also been associated to IFN, RBV, nucleoside and non-nucleoside inhibitors drug resistance. The prevalence of these mutations was studied in HCV RNA samples from chronically HCV-infected drug-naïve patients.

Methods: After amplification of core and NS5B region by nested-PCR, 12 substitutions were analyzed in 266 Venezuelan HCV isolates subtype 1a, 1b, 2a, 2c, 2b, 2j (a subtype frequently found in Venezuela) and $3 a(n=127$ and $n=228$ for core and NS5B respectively), and compared to isolates from other countries $(n=355$ and $n=646$ for core and NS5B respectively).

Results: R70Q and L/C91M core substitutions were present exclusively in HCV G1b. Both substitutions were more frequent in American isolates compared to Asian ones (69\% versus $26 \%, p<0.001$ and $75 \%$ versus $45 \%, p<0.001$ respectively). In Venezuelan isolates NS5B D310N substitution was detected mainly in G3a (100\%) and G1a (13\%), this later with a significantly higher prevalence than in Brazilian isolates $(p=0.03)$. The NS5B mutations related to IFN/RBV treatment D244N was mainly found in G3a, and Q309R was present in all genotypes, except G2. Resistance to new NS5B inhibitors (C316N) was only detected in $18 \%$ of G1b, with a significantly lower prevalence than in Asian isolates, where this polymorphism was surprisingly frequent $(p<0.001)$.

Conclusions: Genotypical, geographical and regional differences were found in the prevalence of substitutions in HCV core and NS5B proteins. The substitutions found in the Venezuelan G2j type were similar to that found in G2a and $\mathrm{G} 2 \mathrm{C}$ isolates. Our results suggest a high prevalence of the R70Q and L/C91M mutations of core protein for G1b and D310N substitution of NS5B protein for the G3a. C316N polymorphism related with resistance to new NS5B inhibitors was only found in G1b. Some of these mutations could be associated with a worse prognosis of the disease in HCV infected patients.
\end{abstract}

Keywords: HCV, Core, NS5B, Mutation

\footnotetext{
* Correspondence: fhpujol@gmail.com

Laboratorio de Virología Molecular, Centro de Microbiología y Biología

Celular, Instituto Venezolano de Investigaciones Científicas, Apdo 20632,

Caracas 1020-A, Venezuela
} 


\section{Background}

Around 170 million persons (3\% of the world population) are infected with the hepatitis $\mathrm{C}$ virus (HCV). More than 350,000 people die from HCV-related liver diseases, including hepatocellular carcinoma (HCC), each year [1]. In Latin America around 7 million persons are infected with $\mathrm{HCV}$ and overall prevalence of $\mathrm{HCV}$ antibodies in non-Amerindian populations from South America is around 1\% [2-4]. About 130 million people in the world are chronically infected with HCV and at risk of developing liver inflammation, fibrosis, cirrhosis and steatosis leading to HCC [1]. Furthermore, in these chronic patients $\mathrm{HCV}$ infection has an increased risk of type-2 diabetes mellitus or insulin resistance (IR) [5].

Seven HCV genotypes, and a large number of subtypes in each genotype, have been described. Genotypes 1, 2, and 3 have a worldwide distribution, and their prevalence varies according to the region of the world. In Venezuela, genotype 1 is the most frequently detected, followed by genotypes 2 and 3, however a significant reduction of HCV G1b circulation was observed in the last decade, with the increase in circulation of genotype G2j, a subtype quite rare in other countries, including the Americas [6,7].

While a vaccine for $\mathrm{HCV}$ is not available, many new antiviral agents are being tested to treat HCV infection, such as nucleoside (NIs) and non-nucleoside (NNIs) polymerase and protease inhibitors. The combination of pegylated interferon alpha (IFN) and ribavirin (RBV), plus new HCV NS3/4A serine protease inhibitors (boceprevir or telaprevir) is the current treatment for patients chronically infected with HCV [8]. HCV genotype is also a predictive parameter for sustained virological response (SVR). Infections with HCV genotype 1 are associated with the lowest therapeutic success [9].

Within the HCV genome, core is thought to be the most conserved protein; results of nucleotide and deduced amino acid sequence analysis across diverse strains of HCV reveal 81-88\% nucleotide and 96\% amino acid sequence homology $[10,11]$. The core gene region plays several essential roles in the $\mathrm{HCV}$ life cycle. Recent studies have revealed that amino acid substitutions in the core region of different HCV genotypes are associated with IR [12], increased HCC risk [13-17], variable responses to double (IFN/RBV) [18-24] and triple (telaprevir plus INF/RBV) therapy $[25,26]$, and liver steatosis [27-30]. On the other hand, the region of the viral genome that codes for NS5B has been described as an important target in therapy with IFN/RBV, and nucleoside and non-nucleoside drugs [31]. Many drugresistance mutations induced by antiviral treatment are located in this region of the genome [32-37].

In the present study, we analyzed core and NS5B polymorphisms/mutations which have been associated with non-responsiveness or a better response to IFN/RBV combination therapy, and/or resistance to polymerase inhibitor drugs, HCC, liver steatosis and IR, in chronically infected drug-naïve patients from Venezuela, and these polymorphisms/mutations were compared with worldwide $\mathrm{HCV}$ isolates.

\section{Results}

Some relevant core and NS5B substitutions associated with treatment response, as well as, with a worse prognosis of the disease were analyzed. Four core substitutions [12-30] and eight NS5B substitutions [32-37] were studied in 266 Venezuelan HCV isolates from chronically infected, drugnaïve patients $(n=127$ and $n=228$ for core and NS5B respectively), and compared to isolates from other countries ( $n=355$ and $n=646$ for core and NS5B respectively).

Core mutations R70Q and L/C91M, associated with IR [12], increased HCC risk [13-17], variable responses to double (IFN/RBV) [18-24] and triple (teleprevir plus INF/ RBV) therapy [25,26], and liver steatosis [27,28], were mainly found in G1b isolates. In Venezuelan isolates, 42\% carried one and 53\% both substitutions (data not shown). These mutations were significantly more frequent in American isolates compared to Asian ones (Table 1). G1a,

\begin{tabular}{|c|c|c|c|}
\hline Genotype & $\begin{array}{l}\text { Geographic } \\
\text { region }\end{array}$ & $\begin{array}{c}\text { R70Q } \\
\text { substitution }\end{array}$ & $\begin{array}{c}\text { L/C91M } \\
\text { substitution }\end{array}$ \\
\hline \multirow[t]{4}{*}{$1 \mathrm{a}$} & V & $1 / 27(3.7 \%)$ & $0 / 27(0 \%)$ \\
\hline & $U$ & 1/27 (3.7\%) & 0/27 (0\%) \\
\hline & $J$ & $0 / 5(0 \%)$ & $0 / 5(0 \%)$ \\
\hline & Ur & $0 / 3(0 \%)$ & 0/3 (0\%) \\
\hline \multirow[t]{7}{*}{$1 b$} & $\mathrm{~V}$ & $30 / 38(79 \%)$ & $26 / 38(68 \%)$ \\
\hline & $\mathbf{U}$ & 20/34 (65\%) & 28/34 (82\%) \\
\hline & Am & $50 / 72(69 \%)$ & $54 / 72(75 \%)$ \\
\hline & J & $32 / 80(40 \%)$ & 25/80 (31\%) \\
\hline & $\mathrm{Ch}$ & $7 / 70(10 \%)$ & $43 / 70(61 \%)$ \\
\hline & As & $39 / 150(26 \%)$ & $68 / 150(45 \%)$ \\
\hline & & $p<0.001$ & $\mathrm{p}<0.001$ \\
\hline $2 a$ & $J$ & $0 / 66(0 \%)$ & $0 / 66(0 \%)$ \\
\hline \multirow[t]{2}{*}{$2 b$} & v & $0 / 3(0 \%)$ & $0 / 3(0 \%)$ \\
\hline & $J$ & $0 / 32(0 \%)$ & 0/32 (0\%) \\
\hline \multirow[t]{2}{*}{$2 c$} & v & $0 / 7(0 \%)$ & $0 / 7(0 \%)$ \\
\hline & RW & 0/20 (0\%) & 0/20 (0\%) \\
\hline $2 j$ & V & $0 / 42(0 \%)$ & $0 / 42(0 \%)$ \\
\hline \multirow[t]{2}{*}{$3 a$} & V & $1 / 10(10 \%)$ & $0 / 10(0 \%)$ \\
\hline & RW & $2 / 18(11 \%)$ & $0 / 18(0 \%)$ \\
\hline
\end{tabular}

V: Venezuela; U: USA; Ur: Uruguay; Am: American countries (USA and Venezuela). As: Asian countries like Ch: China and J: Japan (including prevalence data of Furui et al. [39], for which sequences are not available); RW: Rest of the world. Numbers in bold refer to mutations found at higher frequency compared to other genotypes or locations. P: Statistical significance of prevalence of mutations in isolates from the Americas compared to Asia. 
G2b and G3a presented a Cysteine in position 91 while G2c and G2j a Leucine. In general, both in core and NS5B region, G2j polymorphisms were essentially similar to those found in G2c. Steatosis motives in core domain 3 (amino acids 182 and 186 [29,30]) were exclusive to G3a.

In NS5B region, D310N, D244N, T329I and S326G substitutions have been described to be induced by RBV treatment [33]. D310N was detected mainly in G3a (100\%) and G1a (13\%) Venezuelan samples (Table 2). Interestingly, the presence of this mutation in G1a isolates was significantly higher than that found in Brazilian isolates $(\mathrm{p}=0.03)$. D244N was only found in G3a $(78 \%$ in Venezuela). G2 harbored a Serine in this position. T329I and S326G could only be analyzed in G2 and G3 isolates, since the length of G1 sequences did not allow the analysis of this region. T329I was only found in G2b isolates (100\%), T329A was frequent in G2c and G2j (93\% and $90 \%$ respectively), while T329V was found in G3a (100\%). S326G was no found in the HCV isolates analyzed.

Q309R and A333E NS5B mutations, frequents in patients with SVR and end-of-treatment response (ETR) after INF/RB therapy [32], were also analyzed. Q309R mutation was present in all genotypes (100\% G3a, 44\% G1a and 12\% G1b from Venezuela), except G2 which harbored a Valine in this position (100\% G2a, G2b, G2c and $91 \%$ G2j). This mutation was more frequently found in Brazilian G1a isolates compared to Venezuelan and USA isolates (Table 2). A333E mutation, only analyzed in Venezuelan G2 and G3 isolates, was present in most G2 samples (100\% G2a, G2b, G2c and 98\% G2j from Venezuela). G3a samples harbored Lysine or Arginine substitution at this position.

In addition, in the NS5B region, S282T and C316Y/N substitutions, associated to resistance to new NS5B inhibitors (2'-C-methyl modified ribonucleosides and HCV-796, respectively) [34-37], were also analyzed. S282T mutation (Table 2) and C316Y mutation were not found in any of the HCV isolates analyzed. However, C316N polymorphism was only detected in $18 \%$ of
Venezuelan G1b isolates, in a similar prevalence to that found in other Latin American countries, but with a significantly lower frequency than those found in Japan (Table 2).

Phylogenetic analysis was performed in order to evaluate the genetic relatedness of $\mathrm{G1}$ isolates harboring D310N and C316N substitutions in the NS5B region (Figure 1). Interestingly, most of the $\mathrm{HCV}$ isolates harboring these variants, and particularly G1a isolates with D310N substitution, were associated in clades, displaying more than $98 \%$ of identity. However, G1a Venezuelan isolates harboring these mutations did not group with the Brazilian ones. Some of the clades were composed of isolates from one country, while one clade included isolates from Venezuela and USA (Figure 1).

Others mutations that also confers resistance to others NNIs, have been identified downstream the NS5B region [38]. These mutations could not be analyzed in this study, due to the length of the sequence analyzed.

\section{Discussion}

A total of 12 amino acid positions were analyzed in core [12-30] and/or NS5B region [32-37] of Venezuelan HCV isolates and compared to worldwide isolates. Substitutions in these sites have been related either to IFN/RBV treatment or differential susceptibility to others drugs, and/or to a worse prognosis of the disease [12-30,32-37]. These substitutions were found in $9 / 12$ positions analyzed, with genotypical, geographical and/or regional differences in the prevalence of them.

R70Q and L/C91M core substitutions were found more frequently in Venezuelan and USA G1b isolates, compared to Asian ones. These amino acid substitutions in core region of different $\mathrm{HCV}$ genotypes are associated with increased HCC risk [13-17], variable responses to IFN/RBV therapy [18-24], liver steatosis [27-30] and IR [12]. Treatment with IFN/RBV has been proposed to induce these amino acid mutations [23]. Another possible explanation is that these mutations might be selected

Table 2 Frequency of amino acid substitution in NS5B protein related to resistance to INF/RBV and new inhibitors in HCV Venezuelan isolates compared to worldwide isolates

\begin{tabular}{|c|c|c|c|c|c|c|c|c|c|}
\hline \multirow[b]{3}{*}{ Substitution (related to) } & \multicolumn{9}{|c|}{ Genotypes } \\
\hline & \multicolumn{3}{|c|}{$1 \mathrm{a}$} & \multicolumn{3}{|c|}{$1 b$} & \multicolumn{3}{|c|}{$3 a$} \\
\hline & V & $\mathrm{Br}$ & $\mathbf{U}$ & V & LA & ASIA & $\mathbf{V}$ & LA & $U$ \\
\hline Q309R (INF/RBV) & $36 / 82(44 \%)$ & $\begin{array}{c}67 / 101 \\
(66 \%) p=0.004\end{array}$ & $28 / 70(40 \%)$ & $7 / 61(12 \%)$ & $7 / 104(6.7 \%)$ & 19/335 (5.7\%) & 9/9 (100\%) & 20/22 (91\%) & $21 / 21(100 \%)$ \\
\hline D310N (RBV) & $\begin{array}{c}11 / 82 \\
(13 \%) p=0.03\end{array}$ & 4/101 (4\%) & $3 / 70(4 \%)$ & $1 / 61(1.6 \%)$ & $1 / 104(1 \%)$ & $3 / 335(0.9 \%)$ & $9 / 9$ (100\%) & $20 / 22(91 \%)$ & $20 / 21(95 \%)$ \\
\hline S282T (NI) & 0/82 (0\%) & 0/101 (0\%) & $0 / 70(0 \%)$ & $0 / 61(0 \%)$ & 0/104 (0\%) & 0/335 (0\%) & $0 / 9(0 \%)$ & $0 / 22(0 \%)$ & $0 / 21(0 \%)$ \\
\hline C316N (NNI) & 0/82 (0\%) & 0/101 (0\%) & $0 / 70(0 \%)$ & 11/61 (18\%) & 18/104 (18\%) & $\begin{array}{c}307 / 335 \\
(91.6 \%) p<0.001\end{array}$ & $0 / 9(0 \%)$ & $0 / 22(0 \%)$ & $0 / 21(0 \%)$ \\
\hline
\end{tabular}

V: Venezuela; Br: Brazil; LA: Other Latin-American countries (Brazil, Chile, Colombia and/or Argentina); U: USA; Asia: China, Japan, Hong Kong and Taiwan. Numbers in bold refer to mutations found at higher frequency compared to other genotypes or locations. P: Statistical significance of prevalence of mutations in isolates from Venezuela compared to Brazil (for Q309R and D310N) and from Venezuela and Latin America compared to Asia (C316N). 


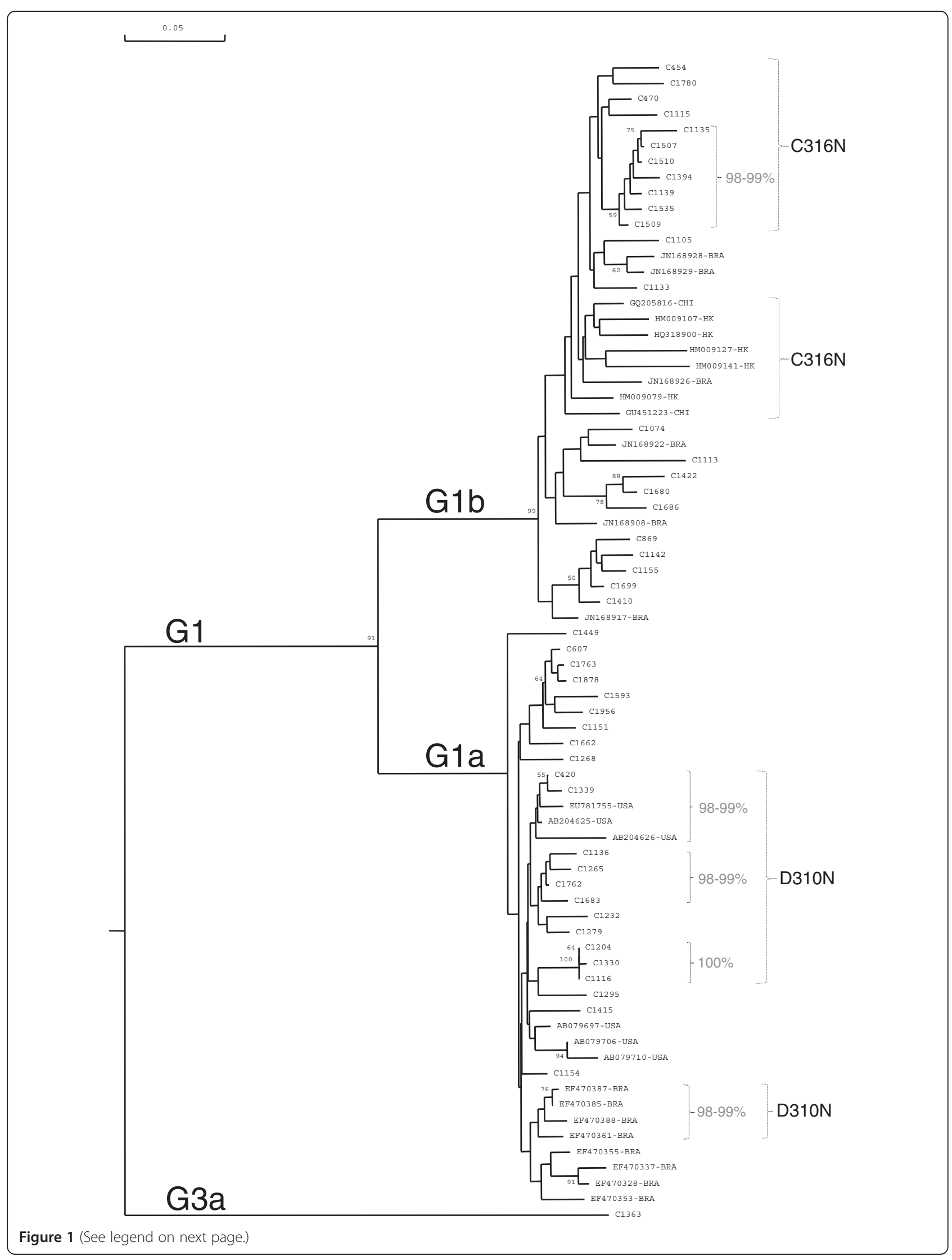


(See figure on previous page.)

Figure 1 Phylogenetic analysis of the NS5B partial genomic region (256 nt, 8302-8556) of HCV G1 strains. Genetic distance was estimated by Kimura 2 parameters and phylogenetic tree was constructed with the Neighbor joining method. Bootstrap values over $50 \%$ are shown in the tree. Isolates are designated by their GenBank accession number, followed by their country of origin, except for Venezuelan ones, which are numbered and preceded by a C. G1a sequences harboring D310N substitution were included, and a similar number of sequences not harboring these mutations, from Venezuela $(n=23)$, Brazil (BRA, $n=8)$ and USA $(n=6)$. The same criteria of selection was applied to G1b sequences, respect to C316N substitution, from Venezuela $(n=23)$, Brazil $(n=6)$ and Asia ( $n=7$ from HK: Hong Kong, JAP: Japan and CHI: China). Sequences grouped in clades containing D310N or C316N substitutions are shown in brackets. Percent identities over $98 \%$ are shown for these clades.

during the natural course of infection, in response to the selective pressure of endogenous IFN [39]. The relatively high frequency of these mutations in patients not treated with IFN/RBV might be associated to the transmission of $\mathrm{HCV}$ isolates from treated patients. In addition, this relative high frequency in Latin America warrants further follow up studies in patients harboring one or two of these mutations. Steatosis motives in core domain 3 were exclusive to G3a, as previously reported [29].

Some mutations have been described in the NS5B region and appeared to be generated during IFN/RBV treatment, probably because of the mutagenic effect of RBV [33]. D310N was detected in all G3a isolates. Interestingly, the frequency of this mutation was higher in Venezuelan G1a compared to Brazilian and USA isolates. Phylogenetic analysis of G1a isolates showed that the isolates carrying D310N were grouped in clades with high genetic relatedness, in agreement with the hypothesis of networks of transmission between non-treated patients infected with $\mathrm{HCV}$ isolates from a treated patient.

In addition, some of these mutations have been found more frequently in viruses infecting patients with sustained virological response (SVR) or during end-oftreatment response (ETR), in which the virus has been persistently or at least temporarily eliminated [32]. From these, the Q309R and A333E mutations were analyzed in this study. In Venezuelan isolates Q309R was present in all genotypes except G2, very frequent in G3 and rare in G1b. In G1a the frequency of this mutation was similar in Venezuelan and USA isolates, but significantly lower than those found in Brazil. Instead, A333E was frequent in G2 and rare in G3, while it could not be analyzed in G1. These results are in agreement with the frequency found in other countries [40]. The presence of these amino acid substitutions might be related to the relative susceptibility to IFN/RBV of G2 and G3 compared to G1.

S282T mutation in the NS5B polymerase is known to confer resistance to the inhibitor 2'-C-methyl modified ribonucleosides [34] with a decrease viral fitness [35]. This mutation was not present in the isolates analyzed in this study.

For NNIs, resistance mutations may also occur as natural variants more frequently in patients infected with a specific subtype. For example, the C316Y mutation in
NS5B is associated most frequently with resistance to HCV-796 [36]. Furthermore, C316N also reduces sensitivity to HCV796 in vitro and this polymorphism is observed in many patients infected with HCV subtype 1b [41-43]. While C316Y mutation was not present in the isolates analyzed, $\mathrm{C} 316 \mathrm{~N}$ variant was detected in $18 \%$ of Venezuelan G1b isolates, with a significantly lower prevalence than in Asian isolates, where this mutation was found at high frequency (Table 2). Again, phylogenetic analysis showed that Venezuelan G1b isolates carrying the $\mathrm{C} 316 \mathrm{~N}$ were generally grouped in clades, displaying high genetic relatedness.

Two major clades have been described inside G1a isolates worldwide [44]. Brazilian isolates belong mainly to one of these clades [45], and even form a cluster inside this clade [46]. Venezuelan HCV isolates do not group together with Brazilian isolates (Figure 1). These results suggest that important regional variations might be found in HCV isolates circulating in South America. An example of this is the predominant circulation of G2j among the G2 isolates circulating in Venezuela, and not found in other neighboring countries [7].

\section{Conclusions}

Genotypical, geographical and regional differences were found in the prevalence of substitutions in HCV core and NS5B proteins. The substitutions found in the Venezuelan G2j type were similar to that found in G2a and G2c isolates. Our results suggest a high prevalence in Venezuela of the R70Q and L/C91M mutations of core protein for G1b and D310N substitution of NS5B protein for the G3a. As expected, C316N polymorphism, associated to resistance to NNIs was only found in G1b, and mutation S282T to NIs was absent. However, the presence of mutations associated to a worse prognosis of the disease in $\mathrm{HCV}$-infected patients warrants further studies to analyze their impact in the clinical outcome of this disease in Venezuela.

\section{Methods}

\section{Blood samples}

Serum samples were collected from 1997 to 2010, from $\mathrm{HCV}$-infected untreated patients after written informed consent, and stored at $-30^{\circ} \mathrm{C}$ until use. This study was approved by the Bioethical Committee of Instituto 
Venezolano de Investigaciones Cientificas (IVIC). A total of 127 Venezuelan samples (27 infected with HCV-1a, 38 HCV-1b, 3 HCV-2b, 7 HCV-2c, 42 HCV-2j and 10 with HCV-3a) were processed for core amplification $(57.5 \%$ male) and 228 (82 infected with HCV-1a, 61 HCV-1b, 1 with HCV-2a, 13 HCV-2b, 9 HCV-2c, 53 HCV-2j and 9 with HCV-3a) for NS5B amplification (58.3\% male).

\section{PCR and sequencing}

HCV RNA was extracted from human plasma sample using a QIAamp ${ }^{\circledR}$ Viral Mini Kit (QIAGEN, Hilden Germany) and reverse-transcribed to complementary DNA using MMLV Reverse Transcriptase (Invitrogen life technologies, USA), according to the manufacturers protocol. HCV genotype was determined by direct sequencing and phylogenetic analysis of a polymerase chain reaction-amplified product from the $5^{\prime}$ non-coding region [6], core and/or NS5B [7]. The NS5B amplicons were generated previously [7]. The core amplified PCR products were purified by using the QIAquick PCR Purification Kit (Qiagen) and then subjected to direct nucleotide sequencing. In all cases, both sense and antisense inner primers were used for sequencing and all sequences were performed by Macrogen Service Center, Seoul, Korea. A total of 127 core sequences were analyzed: 49 obtained previously [7] and 79 from this study.

\section{Determination and analysis of core and NS5B amino acid sequence}

Amino acid sequences were deduced and aligned using MEGA 4.0.2. The NS5B sequences [GenBank accession numbers HM777048-HM777357] and core sequences [GenBank accession numbers HM777360 -HM777430 and JQ924868-JQ924946] of Venezuelan HCV-infected naïve patients were analyzed. The sequences of each genotype from other countries were obtained from GenBank and HCV database (http:VHC.lanl.gov/content/VHC-db/index).

\section{Phylogenetic analysis}

Sequence alignment performed by the global alignment algorithm, using DNAman 5.2.2 (Lynnon Bio Soft, Canada). Phylogenetic analysis was performed by the Neighbor Joining method (1000 bootstrap replicas, with genetic distances estimated with Kimura 2 parameters correction).

\section{Statistical analysis}

Statistical differences were evaluated by the Chi-Squares test with Yates correction, or Fisher Exact test, according to a computerized Epi Info program, version 3.5.3 (Centers for Disease Control and Prevention, Atlanta, GA).

\section{Abbreviations}

ETR: End-of-treatment response; G: Genotype; HCC: Hepatocellular carcinoma; HCV: Hepatitis C virus; IFN: Pegylated Interferon alpha; IR: Insulin resistance;
NIs: Nucleoside inhibitors; NNIs: Non- nucleoside inhibitors; RBV: Ribavirin; SVR: Sustained virological response.

\section{Competing interests}

The authors manifest non competing interests.

\section{Authors' contributions}

RCJ, YFS, MZS, CLL, HRR, and FHP carried out the molecular genetic studies. RCJ, YFS and FHP participated in the sequence alignment and phylogenetic analysis. RCJ and FHP drafted the manuscript. All authors read and approved the final manuscript.

\section{Acknowledgments}

This work was supported by Grant LOCTI from Venezuela.

Received: 30 April 2012 Accepted: 18 September 2012 Published: 21 September 2012

\section{References}

1. World health organization report June 2011, fact sheet $N^{\circ} 164$ : http://www.who.int/mediacentre/factsheets/fs164/en/.

2. Aguilar MS, Cosson C, Loureiro CL, Devesa M, Martínez J, Villegas L, Flores J, Ludert JE, Noya O, Liprandi F, Pujol FH, Alarcón de Noya B: Prevalence of hepatitis $C$ virus infection in Venezuela assessed by a synthetic peptide-based immunoassay. Ann Trop Med Parasitol 2001, 95:187-195.

3. Silva L, Paraná R, Mota E, Cotrim HP, Boënnec-McCurtey ML, Vitvitinsky L, Pádua A, Trepo C, Lyra L: Prevalence of hepatitis C virus in urban and rural populations of northeast brazil - pilot study. Arq Gastroenterol 1995, 32:168-171.

4. Talarmin A, Kazanji M, Cardoso T, Pouliquen J-F, Sankale-Suzanon J, Sarthou $J$ : Prevalence of antibodies to hepatitis $a, C$, and $E$ viruses in different groups in French Guiana. J Med Virol 1997, 52:430-435.

5. Hung CH, Lee CM, Lu SN: Hepatitis C virus-associated insulin resistance: pathogenic mechanisms and clinical implications. Expert Rev Anti Infect Ther 2011, 9(5):525-533.

6. Pujol FH, Loureiro CL: Replacement of hepatitis $C$ virus genotype $1 \mathrm{~b}$ by genotype 2 over a 10 year period in Venezuela. J Clin Gastroenterol 2007 41:518-520.

7. Sulbarán MZ, Di Lello FA, Sulbarán Y, Cosson C, Loureiro CL, Rangel HR, Cantaloube JF, Campos RH, Moratorio G, Cristina J, Pujol FH: Genetic history of hepatitis $C$ virus in Venezuela: high diversity and long time of evolution of HCV genotype 2. PLoS One 2010, 5(12):e14315.

8. Hofmann WP, Zeuzem S: A new standard of care for the treatment of chronic HCV infection. Nat Rev Gastroenterol Hepatol 2011, 8(5):257-264.

9. Fried MW, Hadziyannis SJ, Shiffman ML, Messinger D, Zeuzem S: Rapid virological response is the most important predictor of sustained virological response across genotypes in patients with chronic hepatitis C virus infection. J Hepatol 2011, 55(1):69-75.

10. Davis GL: Hepatitis C virus genotypes and quasispecies. Am J Med 1999, 107:21S-26S.

11. Simmonds P, Smith DB, McOmish F, Yap PL, Kolberg J, Urdea MS, Holmes EC: Identification of genotypes of hepatitis $C$ virus by sequence comparisons in the core, E1 and NS-5 regions. J Gen Virol 1994, 75(Pt 5):1053-1061.

12. Akuta N, Suzuki F, Hirakawa M, Kawamura Y, Yatsuji H, Sezaki H, Suzuki Y, Hosaka T, Kobayashi M, Kobayashi M, Saitoh S, Arase Y, Ikeda K, Kumada H: Amino acid substitutions in the hepatitis $C$ virus core region of genotype $1 \mathrm{~b}$ are the important predictor of severe insulin resistance in patients without cirrhosis and diabetes mellitus. J Med Virol 2009, 81(6):1032-1039.

13. Akuta N, Suzuki F, Seko Y, Kawamura Y, Sezaki H, Suzuki Y, Hosaka T, Kobayashi M, Hara T, Kobayashi M, Saitoh S, Arase Y, Ikeda K, Kumada H: The complicated relationships of amino acid substitution in HCV core region and IL28Bgenotype influencing hepatocarcinogenesis. Hepatology, In press.

14. Fishman SL, Factor SH, Balestrieri C, Fan X, Dibisceglie AM, Desai SM, Benson $G$, Branch AD: Mutations in the hepatitis $C$ virus core gene are associated with advanced liver disease and hepatocellular carcinoma. Clin Cancer Res 2009, 15(9):3205-3213.

15. Hu Z, Muroyama R, Kowatari N, Chang J, Omata M, Kato N: Characteristic mutations in hepatitis $C$ virus core gene related to the occurrence of hepatocellular carcinoma. Cancer Sci 2009, 100(12):2465-2468. 
16. Kobayashi M, Akuta N, Suzuki F, Hosaka T, Sezaki H, Kobayashi M, Suzuki Y, Arase $Y$, Ikeda K, Watahiki S, Mineta R, Iwasaki S, Miyakawa Y, Kumada H: Influence of amino-acid polymorphism in the core protein on progression of liver disease in patients infected with hepatitis $C$ virus genotype 1b. J Med Virol 2010, 82(1):41-48.

17. Nakamoto S, Imazeki F, Fukai K, Fujiwara K, Arai M, Kanda T, Yonemitsu Y, Yokosuka O, Nakamoto S, Imazeki F, Fukai K, Fujiwara K, Arai M, Kanda T, Yonemitsu Y, Yokosuka O: Association between mutations in the core region of hepatitis $C$ virus genotype 1 and hepatocellular carcinoma development. J Hepatol 2010, 52(1):72-78. Erratum in: J Hepatol 2010, 52(4):620.

18. Akuta N, Suzuki F, Hirakawa M, Kawamura $Y$, Sezaki H, Suzuki $Y$, Hosaka T, Kobayashi M, Kobayashi M, Saitoh S, Arase Y, Ikeda K, Chayama K, Nakamura $Y$, Kumada H: Amino acid substitution in HCV core/NS5A region and genetic variation near IL28B gene affect treatment efficacy to interferon plus ribavirin combination therapy. Intervirology 2012, 55(3):231-241.

19. Akuta N, Suzuki F, Sezaki H, Suzuki Y, Hosaka T, Someya T, Kobayashi M, Saitoh S, Watahiki S, Sato J, Matsuda M, Kobayashi M, Arase Y, Ikeda K, Kumada $\mathrm{H}$ : Association of amino acid substitution pattern in core protein of hepatitis $C$ virus genotype $1 \mathrm{~b}$ high viral load and non-virological response to interferon-ribavirin combination therapy. Intervirology 2005, 48(6):372-380.

20. Fukuhara T, Taketomi A, Okano S, Ikegami T, Soejima Y, Shirabe K, Maehara $Y$ : Mutations in hepatitis $C$ virus genotype $1 b$ and the sensitivity of interferon-ribavirin therapy after liver transplantation. J Hepatol 2010, 52(5):672-680.

21. Inoue $Y$, Hiramatsu N, Oze T, Yakushijin T, Mochizuki K, Fukuda K, Mita E, Haruna $Y$, Inoue A, Imai $Y$, Hosui A, Miyagi T, Yoshida $Y$, Tatsumi T, Kiso S, Kanto T, Kasahara A, Takehara T, Hayashi N: Amino acid substitution in the core protein has no impact on relapse in hepatitis $C$ genotype 1 patients treated with peginterferon and ribavirin. J Med Virol 2011, 83(3):419-427.

22. Kumthip K, Pantip C, Chusri P, Thongsawat S, O'Brien A, Nelson KE, Maneekarn N: Correlation between mutations in the core and NS5A genes of hepatitis $C$ virus genotypes $1 \mathrm{a}, 1 \mathrm{~b}, 3 \mathrm{a}, 3 \mathrm{~b}, 6 \mathrm{f}$ and the response to pegylated interferon and ribavirin combination therapy. $J$ Viral Hepat 2011, 18(4):e117-e125.

23. Kurbanov F, Tanaka Y, Matsuura K, Sugauchi F, Elkady A, Khan A, Hasegawa I, Ohno T, Tokuda H, Mizokami M: Positive selection of core $70 \mathrm{Q}$ variant genotype $1 \mathrm{~b}$ hepatitis $C$ virus strains induced by pegylated interferon and ribavirin. J Infect Dis 2010, 201:1663-1671.

24. Akuta N, Suzuki F, Hirakawa M, Kawamura Y, Yatsuji H, Sezaki H, Suzuki Y, Hosaka T, Kobayashi M, Kobayashi M, Saitoh S, Arase Y, Ikeda K, Kumada H: Association of amino acid substitution pattern in core protein of hepatitis $C$ virus genotype 2 a high viral load and virological response to interferon-ribavirin combination therapy. Intervirology 2009, 52(6):301-309.

25. Akuta N, Suzuki F, Hirakawa M, Kawamura Y, Yatsuji H, Sezaki H, Suzuki Y, Hosaka T, Kobayashi M, Kobayashi M, Saitoh S, Arase Y, Ikeda K, Kumada H: Amino acid substitutions in the hepatitis $C$ virus core region of genotype $1 \mathrm{~b}$ affect very early viral dynamics during treatment with telaprevir, peginterferon, and ribavirin. J Med Virol 2010, 82(4):575-582

26. Akuta N, Suzuki F, Hirakawa M, Kawamura Y, Yatsuji H, Sezaki H, Suzuki $Y$, Hosaka T, Kobayashi M, Kobayashi M, Saitoh S, Arase Y, Ikeda K, Chayama K, Nakamura Y, Kumada $\mathrm{H}$ : Amino acid substitution in $\mathrm{HCV}$ core region and genetic variation near the IL28B gene affect viral dynamics during telaprevir, peginterferon and ribavirin treatment. Intervirology 2012, 55(6):417-425

27. Tachi $Y$, Katano $Y$, Honda T, Hayashi K, Ishigami M, Itoh A, Hirooka Y, Nakano I, Samejima Y, Goto H: Impact of amino acid substitutions in the hepatitis $\mathrm{C}$ virus genotype $1 \mathrm{~b}$ core region on liver steatosis and hepatic oxidative stress in patients with chronic hepatitis C. Liver Int 2010 30(4):554-559.

28. Sumida Y, Kanemasa K, Hara T, Inada Y, Sakai K, Imai S, Yoshida N, Yasui K, Itoh Y, Okanoue T, Yoshikawa T: Impact of amino acid substitutions in hepatitis $C$ virus genotype $1 \mathrm{~b}$ core region on liver steatosis and glucose tolerance in non-cirrhotic patients without overt diabetes. $J$ Gastroenterol Hepatol 2011, 26(5):836-842.

29. Jhaveri R, McHutchison J, Patel K, Qiang G, Diehl AM: Specific polymorphisms in hepatitis $C$ virus genotype 3 core protein associated with intracellular lipid accumulation. J Infect Dis 2008, 197(2):283-291.
30. Jhaveri R, Qiang G, Diehl AM: Domain 3 of hepatitis $C$ virus core protein is sufficient for intracellular lipid accumulation. $J$ Infect Dis 2009, 200(11):1781-1788.

31. Varshney J, Sharma PK, Sharma A: A review on an update of NS5B polymerase hepatitis C virus inhibitors. Eur Rev Med Pharmacol Sci 2012, 16(5):667-671.

32. Hamano K, Sakamoto N, Enomoto N, Izumi N, Asahina Y, Kurosaki M, Ueda E, Tanabe Y, Maekawa S, Itakura J, Watanabe H, Kakinuma S, Watanabe M: Mutations in the NS5B region of the hepatitis $C$ virus genome correlate with clinical outcomes of interferon-alpha plus ribavirin combination therapy. J Gastroenterol Hepatol 2005, 20(9):1401-1409.

33. Asahina $Y$, Izumi N, Enomoto N, Uchihara M, Kurosaki M, Onuki $Y$, Nishimura Y, Ueda K, Tsuchiya K, Nakanishi H, Kitamura T, Miyake S: Mutagenic effects of ribavirin and response to interferon/ribavirin combination therapy in chronic hepatitis C. J Hepatol 2005, 43(4):623-629.

34. Migliaccio G, Tomassini JE, Carroll SS, Tomei L, Altamura S, Bhat B, Bartholomew L, Bosserman MR, Ceccacci A, Colwell LF, Cortese R, De Francesco R, Eldrup AB, Getty KL, Hou XS, LaFemina RL, Ludmerer SW MacCoss M, McMasters DR, Stahlhut MW, Olsen DB, Hazuda DJ, Flores $\mathrm{OA}$ : Characterization of resistance to non-obligate chain-terminating ribonucleoside analogs that inhibit hepatitis $C$ virus replication in vitro. J Biol Chem 2003, 278(49):49164-49170.

35. Dutartre H, Bussetta C, Boretto J, Canard B: General catalytic deficiency of hepatitis $C$ virus RNA polymerase with an S282T mutation and mutually exclusive resistance towards 2'-modified nucleotide analogues. Antimicrob Agents Chemother 2006, 50(12):4161-4169.

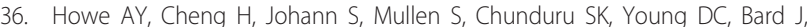
Chopra R, Krishnamurthy G, Mansour T, O'Connell J: Molecular mechanism of hepatitis $C$ virus replicon variants with reduced susceptibility to a benzofuran inhibitor, HCV-796. Antimicrob Agents Chemother 2008, 52(9):3327-3338.

37. McCown MF, Rajyaguru S, Kular S, Cammack N, Nájera I: GT-1a or GT-1b subtype-specific resistance profiles for hepatitis $C$ virus inhibitors telaprevir and HCV-796. Antimicrob Agents Chemother 2009, 53(5):2129-2132.

38. Margeridon-Thermet $S$, Shafer RW: Comparison of the mechanisms of drug resistance among HIV, hepatitis B, and hepatitis C. Viruses 2010, 2(12):2696-2739.

39. Furui $Y$, Hoshi $Y$, Murata K, Ito K, Suzuki K, Uchida S, Satake M, Mizokami $M$, Tadokoro $K$ : Prevalence of amino acid mutation in hepatitis $C$ virus core region among Japanese volunteer blood donors. J Med Virol 2011, 83(11):1924-1929.

40. Castilho MC, Martins AN, Horbach IS, Perez Rde M, Figueiredo FA, Pinto Pde T, Nabuco LC, de Lima DB, Tanuri A, Porto LC, Ferreira Júnior Oda C: Association of hepatitis $C$ virus NS5B variants with resistance to new antiviral drugs among untreated patients. Mem Inst Oswaldo Cruz 2011, 106(8):968-975.

41. Hang JQ, Yang Y, Harris SF, Leveque V, Whittington HJ, Rajyaguru S, Ao-leong G, McCown MF, Wong A, Giannetti AM, Le Pogam S, Talamás F, Cammack N, Nájera I, Klumpp K: Slow binding inhibition and mechanism of resistance of non-nucleoside polymerase inhibitors of hepatitis C virus. J Biol Chem 2009, 284(23):15517-15529.

42. Le Pogam S, Seshaadri A, Kosaka A, Chiu S, Kang H, Hu S, Rajyaguru S, Symons J, Cammack N, Nájera I: Existence of hepatitis C virus NS5B variants naturally resistant to non-nucleoside, but not to nucleoside, polymerase inhibitors among untreated patients. Antimicrob Chemother 2008, 61(6):1205-1216.

43. Plaza Z, Soriano V, Gonzalez Mdel M, Di Lello FA, Macias J, Labarga P, Pineda JA, Poveda E: Impact of antiretroviral therapy on the variability of the HCV NS5B polymerase in HIV/HCV co-infected patients. J Antimicrob Chemother 2011, 66(12):2838-2842.

44. Pickett BE, Striker R, Lefkowitz EJ: Evidence for separation of HCV subtype 1a into two distinct clades. J Viral Hepat 2011, 18(9):608-618.

45. Lampe E, Espirito-Santo MP, Martins RM, Bello G: Epidemic history of hepatitis C virus in brazil. Infect Genet Evol 2010, 10(7):886-895.

46. Peres-da-Silva A, Almeida AJ, Lampe E: Genetic diversity of NS3 protease from Brazilian HCV isolates and possible implications for therapy with direct-acting antiviral drugs. Mem Inst Oswaldo Cruz 2012, 107(2):254-261.

doi:10.1186/1743-422X-9-214

Cite this article as: Jaspe et al:: Prevalence of amino acid mutations in hepatitis $C$ virus core and NS5B regions among Venezuelan viral isolates and comparison with worldwide isolates. Virology Journal 2012 9:214. 